\title{
IMPACTOS DOS HÁBITOS ALIMENTARES NA SAÚDE BUCAL DA CRIANÇA: REVISÃO DE LITERATURA
}

\author{
Impacts Of Food Habits On Child's Oral Health: Literature Review
}

Emanuella Julia da Silva Ryba ${ }^{1}$, Jaqueline Rafaela Silva dos Santos $\stackrel{1}{ }$, Carla Oliveira Favretto ${ }^{2 *}$

\begin{abstract}
RESUMO
Cárie dentária em pacientes em idade pré-escolar tem sido alvo de diversas pesquisas e a alimentação mostrou ter um papel decisivo para o crescimento e o desenvolvimento desta doença. A criança passa por um acelerado processo de maturação biológica e uma boa dieta trará inúmeros benefícios ao indivíduo, como diminuição de doenças como diabetes, doenças coronarianas, obesidade, problemas periodontais e também a cárie dentária. A compreensão da relação existente entre uma boa dieta alimentar iniciada desde cedo e o desenvolvimento da cárie é essencial para o bem-estar físico e social da criança. O objetivo desse trabalho é mostrar através de uma revisão de literatura os impactos dos hábitos alimentares na saúde bucal da criança, orientar os cuidados alimentares necessários em pacientes pediátricos desde as primeiras visitas ao consultório odontológico, evidenciando a relação da dieta alimentar com o desenvolvimento da cárie. Para a síntese da revisão foi realizado um estudo bibliográfico no período de 1991 a 2018, nas bases de dados Pubmed, Scielo, Biblioteca Virtual em Saúde e Google acadêmico, usando os descritores: saúde bucal, dieta e promoção de saúde. Depois da aplicação de critérios de inclusão e exclusão, foram selecionados 61 artigos. A cavidade bucal das crianças apresenta algumas características que podem contribuir para o aparecimento de cárie precoce e hábitos alimentares inadequados podem acelerar o desenvolvimento desta doença. O controle da alimentação será um fator primordial para a manutenção da saúde geral e bucal do paciente, bem como iniciador de problemas de saúde. O cuidado está na seleção do alimento, na quantidade e forma que é ingerido, pois, uma alimentação carogênica altera o esmalte dentário tornando-o mais susceptível a doença cárie. Assim, conclui-se que a orientação e prática de bons hábitos alimentares e uma boa higiene bucal iniciado está precocemente atrelado ao controle e redução do aparecimento da doença cárie em pacientes pediátricos. Para isso é necessário levar o conhecimento aos pais sobre a importância da introdução de uma alimentação correta desde os primeiros anos de vida.

Palavras-chave: Saúde bucal, Higiene bucal, hábito alimentar, prevenção primária.
\end{abstract}

\section{ABSTRACT}

Dental cavity on under school-aged patients, has been the subject for numerous researches, alimentation showed up to have a decisive role on the rise and development of this disease. Children go through a fast process of biological maturation and a healthy diet will benefit them in countless ways, for example, it would lower cases of diabetes, coronarian diseases, obesity, periodontal problems and dental cavity. The comprehension of the relation between early healthy alimentation and the development of dental cavity is fundamental to the child's physical and social well being. This thesis aims to show, through the literary review, the impacts of eating habits on a child's oral health, to guide the food care needed by pediatric patients since their first visit at the dental clinic, evidencing the relation between alimentation and dental cavity. The synthesis of this literary review was made on 1995 to 2018 date range, with Pubmed, Scielo, Biblioteca Virtual em Saúde and Scholar Google databases, using the description "saúde bucal", "dieta e promoção da saúde", resulting in 60 selected papers. Dental cavity on children shows aspects that prone to hasten an early case of caries, as well as inadequate eating habits. The control over the patient eating habits will be a fundamental factor to maintain his mouth and general health. The care is in the selection of the food, on its quantity and the way its eaten, cause cariogenic eating habits will mutate tooth enamel, causing it to be more susceptible to caries. This way, we reckon that the orientation and the early practice of good mouth hygiene and healthy oral habits is directly related to the reduction of caries cases on pediatric patients. To accomplish that its required to bring knowledge to the children parents about the importance of introduction of a correct alimentation since the first years of a children's life.

Keywords: Mouth health, mouth hygiene, eating habits, primary prevention.

1. Graduanda da faculdade de Odontologia de Mineiros, FAMP- Faculdade Morgana Potrich, 75830-000 Mineiros-GO, Brasil.

2. Doutora em Ciência Odontológica - Saúde Bucal da Criança Faculdade de Odontologia de Araçatuba-SP, UNESP, Professora de Odontopediatria, FAMP-

Faculdade Morgana Potrich, 75830-000 Mineiros-GO, Brasil.

*Autor para Correspondência. E-mail: carla.favretto@gmail.com 


\section{INTRODUÇÃO}

Alimentação desempenha um papel decisivo para o crescimento e o desenvolvimento físico da criança em idade pré-escolar. Época em que ela passa por um processo acelerado de maturação biológica, com desenvolvimento social e psicomotor, para o qual a participação da família é fundamental, pois a alimentação aprendida na infância poderá influenciar seu comportamento em relação a hábitos de saúde na idade adulta ${ }^{1}$.

Uma boa dieta contribui para redução de doenças, bem como para sua prevenção. Por outro lado, para ter uma correta saúde bucal é essencial a ingestão de alimentos saudáveis e uma boa higienização bucal com correta escovação e uso do fio dental, contribuindo assim para uma possível redução de diversas doenças bucais como a cárie dentária².

Os benefícios dessa boa alimentação diminuem não só os riscos de cárie dentária e doenças periodontais, como de outras doenças crônicas que compartilham este mesmo fator de risco, tais como diabetes, doenças coronarianas, trigliceridemia, aterosclerose, hiperlipidemia, câncer ${ }^{3}$. Além disso, uma dieta adequada, balanceada e variada, contêm todos os nutrientes indispensáveis para o desenvolvimento infantil e na formação e manutenção de uma dentição saudável ${ }^{7}$.

O desequilíbrio na saúde bucal está diretamente ligado a uma alimentação insatisfatória. A relação entre alimentação com alto teor de açúcar e a cárie dentária tem sido bastante estudada. Pode se afirmar que as crianças que ingerem mais alimentos doces tendem a ter mais cárie dentárias quando comparadas a crianças que não consomem, o que acarreta num elevado índice CPOD (Dentes Careados, Perdidos ou Obturados) $)^{5}$.

As principais doenças ocasionadas pela má alimentação tanto na saúde geral como na saúde bucal diminuem a qualidade de vida das crianças, causando dor, desconforto, prejuízos estéticos, infecções agudas e crônicas, perturbação do sono e da alimentação ${ }^{7}$. Bons hábitos e componentes relacionados à saúde exercem um papel importante na saúde geral e bucal da criança e do adulto. Desenvolver e mantê-los de acordo com padrões adequados podem auxiliar a preservação do indivíduo ao longo da vida ${ }^{8}$.

Dessa forma, o objetivo deste trabalho é através de uma revisão de literatura ressaltar os impactos dos hábitos alimentares na saúde bucal da criança, orientar os cuidados alimentares necessários em pacientes pediátricos desde as primeiras visitas ao consultório odontológico, evidenciando a relação da dieta alimentar com o desenvolvimento da cárie.

\section{MATERIAIS E MÉTODOS}

Foi realizado um estudo de revisão de literatura, onde foram encontrados aproximadamente 136 artigos dos quais 61 foram selecionados para confecção do trabalho, no período específico de 1991 a 2018, nas bases de dados eletrônica Pubmed, Biblioteca Virtual em Saúde, Scientific Electronic Library Online (Scielo) e Google acadêmico.

A busca nos bancos de dados foi realizada utilizando os Descritores em Ciências da Saúde (DeCS). Os unitermos utilizados foram saúde bucal, dieta e promoção de saúde. Os critérios de inclusão foram artigos publicados tanto escritos na língua inglesa, portuguesa e espanhola. Podendo ser pesquisa de campo, relato de caso ou revisão da literatura e os critérios de exclusão foram artigos sem relação com o objetivo do estudo, com a metodologia inadequada ou incompleta e artigos não disponíveis na íntegra.

\section{REVISÃO DA LITERATURA \\ Dieta alimentar versus Cárie Dentária}

Atualmente, a relação direta entre a saúde geral e bucal do paciente vem se tornando algo de relevância para o contexto do bem-estar. Um dos fatores que se destacam nesse processo é a alimentação, que quando balanceada é o segredo para uma vida saudável, evitando o surgimento de diferentes tipos de doenças.

A saúde da cavidade oral repercute no bem-estar do organismo todo, principalmente pelo aspecto nutricional do paciente. $O$ controle dessa alimentação será o fator primordial para manutenção da saúde geral e bucal do paciente bem como iniciador de problemas de saúde.

Uma das doenças que mais atingem a população de países subdesenvolvidos é a cárie dentária. Refere-se a uma doença multifatorial envolvendo fatores psicossociais e biológicos, mas apresenta um fator causal determinante: a presença de açúcares livres ${ }^{9,10}$. Atrelados a formação da cárie dentária na cavidade bucal pode estar presente outras doenças não transmissíveis, como o câncer de boca, labirintites e doenças cardiovasculares. ${ }^{13}$.

A cavidade bucal das crianças apresenta características especificas como uma flora bacteriana recémformada, sistema imunológico imaturo, baixa resistência dos dentes recém erupcionados. Os hábitos alimentares inadequados fazem com que a cárie dentária precoce seja ainda mais prejudicial à saúde uma vez que pode acelerar todo processo fisiopatológico ${ }^{14}$.

A alimentação é a principal variável responsável pela doença infecciosa cárie dentária, dado que influencia diretamente na produção de ácidos, na quantidade e tipo do 
biofilme bacteriano, na composição de microrganismos presentes na cavidade bucal e na qualidade e quantidade de secreção salivar ${ }^{15}$.

O principal carboidrato responsável pela queda rápida, queda do ph e consequentemente a mudança da composição da matriz é a sacarose. Quando exposto frequentemente a esse açúcar ocorre a produção contínua de ácido, o que causa a desmineralização da estrutura dentária. Esta desmineralização do esmalte realiza parte do processo de formação das lesões cariosas e é causada por bactérias acidogênicas que fermentam os carboidratos encontrados na alimentação ${ }^{16}$.

A partir dos carboidratos fermentáveis como a sacarose e a glucose é fornecido para as bactérias cariogênicas um meio de proliferação ideal ${ }^{17}$. Esse aspecto é considerado de grande importância na etiologia da cárie dentária. Estudos sobre inúmeros alimentos mostraram que o aumento na frequência da inserção de açúcar na alimentação aumenta o risco de desmineralização do esmalte além de diminuir o tempo necessário para a sua remineralização efetuada pela saliva, o que favorece o aparecimento de lesões cariosas $^{18}$.

Para Sheiham ${ }^{12}$ o consumo de açúcar está diretamente associado ao crescimento da quantidade de lesões cariosas, uma vez que em países em que houve a prevalência do aumento de cárie houve também um aumento na quantidade per capita do consumo deste produto. A justificativa usada para isso é a de que a ingestão de carboidratos facilita o processo de desmineralização do esmalte, além de exercer seu efeito cariogênico localmente na superfície dentária.

Um grupo de 69 crianças de um a cinco anos foi estudado por Scalioni e outros autores, ${ }^{19}$ e a prevalência de cárie foi de $87 \%$. Dentre as 60 crianças que possuíam cárie dentária foi visto que a ingestão diária de carboidrato era alta em comparação às crianças sem cárie. Após a análise feita observou que os alimentos e as bebidas mais ingeridos eram pães, biscoito, macarrão, doces, achocolatados e suco, além de "salgadinhos" que eram normalmente consumidos entre as principais refeições"6.

Há o registro na literatura de um estudo clássico que mostra a relação existente entre o consumo de sacarose e o aumento de lesões cariosas devido à frequência da ingestão deste carboidrato entra as refeições e da sua forma pegajosa permitir um longo período de permanência na cavidade bucal, ampliando assim o seu efeito cariogênico ${ }^{21}$.

Os açúcares comuns na alimentação (sacarose, glicose, frutose e lactose) são utilizados no metabolismo energético das bactérias presentes na placa bacteriana, devido a isso estão sujeitos a serem usados no processo de fermentação desses microrganismos ${ }^{22}$.

\section{A importância da alimentação na saúde bucal}

A saúde bucal, em geral, está relacionada a diversos fatores, dentre eles se destaca os hábitos alimentares. Este aspecto também interfere na saúde geral do paciente, já que doenças cardíacas, obesidade, gastrite, anemia nutricional, entre outros são agravadas diante de uma alimentação desequilibrada ${ }^{23}$.

Segundo evidências científicas, a saúde está mais ligada ao modo e hábitos de vida da população do que a genética ou determinação biológica. Devido a isso a solução para os problemas alimentares e nutricionais se encontra na promoção de hábitos de vida saudáveis atrelados a estratégias que apoiem a população a cuidar de si, da sua família e de sua comunidade com ações conscientes e participativas. ${ }^{24}$.

Os hábitos alimentares vão influenciar no acarretamento de doenças infecciosas na cavidade oral, como a cárie dentária e doenças periodontais, além de interferir no desenvolvimento crânio encefálico e aparecimento de doenças como o cancro da boca ${ }^{25}$.

Há estudos que mostram a influência da introdução precoce no consumo de açúcar e a doença cárie. Visto que os dentes durante e logo após a sua erupção estão mais vulneráveis a doença e esse período coincide com a época de desmame das crianças. Westover et al. (1989) recomendaram estratégias preventivas, como restrição de açúcar e uso criterioso de flúor ${ }^{26,27}$.

A deficiência nutricional pode levar a ocorrência de defeito na estrutura dos dentes ou atraso na erupção durante o período de formação, além de causar alteração nas glândulas salivares. Após a erupção dos dentes os açúcares e ácidos na alimentação continuam sendo prejudicial, dado que podem causar cárie dentária e erosão no esmalte dos dentes, respectivamente $^{28}$. A cavidade bucal é susceptível a alterações anatômicas e fisiológicas quando ocorre carências ou excessos de nutrientes ${ }^{29}$.

Alguns hábitos alimentares trazem grandes benefícios para a saúde bucal, como a inclusão de alguns grupos de alimentos ricos em fibras, sendo os grãos, vegetais e algumas frutas, já que auxiliam na diminuição da placa bacteriana. Outra fonte importante para manter a cavidade bucal saudável são os lácteos, pois apresentam abundância de cálcio e proteínas ${ }^{30}$. Além disso, os alimentos ricos em vitamina $\mathrm{C}$, proporcionam o aumento da imunidade e possibilitam manter as gengivas saudáveis ${ }^{31}$.

Para o Grupo de Estudos do COMA (Comitee on Medical Aspects of Food Policy), os alimentos 
recomendados durante o período de desmame do bebê são aqueles livres ou com baixo teor de açúcares não lácteos. Também deve ter o cuidado em restringir os alimentos e bebidas cariogênicas para o período das principais refeições, se atentando a não consumir diariamente. Esses açúcares devem ser limitados a cerca de $10 \%$ do valor energético total consumido $^{32}$.

Outro elemento de grande importância para determinar a cariogenicidade de um alimento é o seu grau de solubilidade. Quando baixo, os restos alimentares ficam aderidos à superfície dentária por mais tempo, o que aumenta o seu potencial cariogênico. A frequência em que esse alimento é ingerido e o seu tempo de remoção também irão influenciar na cariogenicidade ${ }^{21}$.

Quando é feita a comparação entre os carboidratos, a sacarose apresenta-se com maior potencial cariogênico, isso se dá pelo pequeno tamanho das moléculas que facilita sua difusão pela placa bacteriana ${ }^{33}$. Ainda assim, este potencial cariogênico pode ser aumentado quando atrelado ao amido, o que é o caso de alimentos como os cereais adocicados, bolos, bolachas doces e biscoitos ${ }^{22}$.

Formada por glicose e galactose, a lactose é o principal açúcar encontrado no leite e seus derivados, possui apenas $1 / 3$ do potencial adoçante da sacarose o que faz dele um alimento não cariogênico. A sacarose é composta por uma unidade de glicose e uma unidade de frutose, sendo a categoria de açúcar mais comum; genericamente, quando se referem os "açúcares", é o teor de sacarose que está em causa. Os amidos são constituídos por cadeias de polissacarídeos, possuindo uma estrutura modificável quando hidrolisados ${ }^{34}$. Este tipo de hidratos de carbono, quando consumido diariamente atrelado a sacarose, pode potencializar o efeito cariogênico por interferir na adesão da microflora oral, sendo essencial na colonização $0^{35}$.

Alimentos saudáveis como frutas, grãos e vegetais apresentam ainda amostras de que são protetores e que atuam como agentes anticariogênicos. Essas amostras são de predominância em alimentos não refinados e são como, por exemplo, os fosfatos orgânicos, fosfatos inorgânicos, polifenóis, fitatos e outras fibras não digeridas. Alimentos fibrosos estimulam o fluxo salivar e, como parte de uma alimentação saudável, são de extrema importância para a saúde bucal ${ }^{30}$.

$\mathrm{Na}$ orientação para a população brasileira há ainda uma observação quanto a alguns produtos alimentícios derivados do leite, como iogurtes e bebidas lácteas industrializadas com sabores, que contêm uma grande quantia de açúcar incorporado em seu preparo, e que devem ser trocados por iogurtes naturais. Este alerta serve para a prevenção da cárie, havendo a evidência da função deste tipo de alimento na desmineralização do esmalte dentário. ${ }^{36}$ Os sucos e purês de frutas podem corresponder os primeiros alimentos não-lácteos oferecidos ao bebê, no horário do lanche, seguidos pela amamentação. ${ }^{37}$

\section{Como introduzir a alimentação para manutenção}

\section{da saúde bucal}

Introdução alimentar é o momento que iniciamos uma nova fase na alimentação do bebê com diversos alimentos além do próprio leite. Até o sexto mês de vida, a Organização Mundial de Saúde (OMS) e do Ministério da Saúde recomenda o aleitamento exclusivo ${ }^{38}$. Após essa idade, inicia a introdução de outros alimentos na dieta, de maneira que o aleitamento ocorra até os dois anos. ${ }^{39}$ É nessa fase que se torna propício à introdução de hábitos alimentares. Contribuindo para que a criança desenvolva um controle dietético saudável, diminuindo o risco de hipertensão, colesterol alto, diabetes, entre outras doenças.

A OMS publicou uma revisão sobre estudos que recomendam que o aleitamento materno salienta benefícios a longo $\mathrm{prazo}^{40}$. Este estudo indica que os sujeitos amamentados exibem pressões sistólica e diastólica mais baixas, níveis menores de colesterol total e risco 37\% menor de apresentar diabetes tipo 2. Não só os sujeitos que são amamentados obtêm proteção contra diabetes, mas também a mulher que amamenta. Foi apresentada uma redução de 15\% na ocorrência de diabetes tipo 2 para cada ano de lactação. ${ }^{39}$ Considera-se essa proteção a uma melhor homeostase da glicose em mulheres que amamentam. $\mathrm{O}$ contato precoce ao leite de vaca (antes dos quatro meses) é julgada um importante decisivo do Diabetes mellitus Tipo I, sendo capaz de aumentar o perigo de seu aparecimento em 50\%. Avaliase que $30 \%$ dos casos teriam potencial de ser prevenidos se $90 \%$ das crianças até três meses não recebessem leite de vaca. $^{38}$

Bons costumes alimentares envolvem a mudança de alimentos industrializados por uma alimentação nativa, isto é, acrescentar comidas que não sofrem inclusão de ingredientes na sua produção, como os conservantes, aromatizantes e os que dão gosto a comidas. Muito açúcar é acrescentado na maioria das comidas industrializadas, incluindo a sacarose que em contato com a superfície dentária é fermentada por microrganismos que existem na placa bacteriana, formando ácidos que dissolvem o esmalte e dá início a cárie ${ }^{41}$.

A recomendação dietética durante o desmame deve conceituar também as exigências nutricionais essenciais ao crescimento e ao desenvolvimento infantil. Os alimentos do 
desmame devem ser iniciados de pouco a pouco, desejando observar a tolerância individual e a aceitabilidade dos novos sabores. ${ }^{42}$. Além disto deve ser ofertada sem rigidez de horários, respeitando-se sempre a vontade da criança. ${ }^{43}$

Deve ser impedir o consumo de açúcares durante o desmame, pois rotinas de alimentos impróprios estabelecidos nesse momento tendem a serem presentes por toda a vida. Para Westover et al. ${ }^{44}$ os vegetais devem ser iniciados antes das frutas, pois deste modo a criança consegue aceitar os vegetais antes de desenvolver o paladar para as frutas doces.

Esta refeição ainda agora iniciada deve ser fornecida à criança ao longo do dia com diversos tipos de comidas, de preferência um alimento de cor viva e variada. Esta refeição acrescentada deve ser consistente desde início e ofertada de colher; primeiramente com consistência pastosa (papas/purês) e, de pouco a pouco, e ir ampliando a consistência até se chegar à refeição da família. ${ }^{43}$

É considerável incentivar o consumo diário de frutas, verduras e legumes na alimentação. Além de que, comidas com grande acúmulo de carboidratos complexos, como grãos (incluindo arroz, milho e trigo), pães, massas, tubérculos (como batatas e inhame) e raízes (como a mandioca) e os alimentos vegetais ricos em proteínas (particularmente os cereais integrais, as leguminosas e também as sementes e (castanhas) $)^{45}$.

Tão importante quanto conhecer a maneira correta de introduzir um alimento é entender também o que deve ser evitado, como por exemplo, comidas com aspecto pegajoso, pois se encontra mais tempo na boca em processo de fermentação, favorecendo o aumento de bactérias responsáveis pela cárie, do que comidas líquidas ou menos pegajosas. Além de aumentar, a capacidade de diminuir o $\mathrm{pH}$ durante o consumo, também deve ser apontada para analisar o potencial cariogênico. ${ }^{46}$

A ingestão de ingredientes com $\mathrm{pH}$ menor do considerado como crítico para o esmalte, pode ocasionar o rompimento da hidroxiapatita. Este desgaste dentário, pode ser resultado de fontes extrínsecas, como a ingestão de refeições com um teor ácido, como refrigerantes, alimentos adocicados, sucos de frutas, entre outros. ${ }^{47}$

Comidas aos quais são acrescentados açúcares, durante o preparo alimentar para alterar o sabor e textura, e comidas como sumos de fruta, o mel, os xaropes e o próprio açúcar branco ou amarelo têm açúcares livres e por isso são cariogênicos e devem ser evitados. ${ }^{48}$

$\mathrm{O}$ aumento da ingestão de refrigerantes, bebidas desportivas, sumos de fruta e leite (excluindo as fórmulas infantis) no primeiro ano de vida, está agregado ao maior do risco de cárie dentária. ${ }^{49}$ Os pais de bebês devem ser orientados sobre o risco da cárie da mamadeira, e as mães devem ser ensinadas a não agregar nenhuma comida ou bebida à mamadeira, com exceção ao leite artificial, materno ordenhado, de vaca ou água ${ }^{50}$.

As refeições podem também resultar em serem uma proteção contra a cárie dentária. Têm sido associados alguns estudos com a intenção de apresentar o papel bioactivo de componentes dos lacticínios na prevenção da cárie dentária ${ }^{51}$. O leite e outros produtos lácteos, especificamente o queijo, têm sido apresentados como comida cariostáticos ${ }^{52}$ pois além de diminuírem os impactos dos ácidos da boca, têm resultado de cuidar sobre a dentina. Rugg-Gunn ${ }^{53}$ relata ainda em uma de suas buscas, que a ingestão de queijo após ingerir uma comida rico em açúcares simples cresce o $\mathrm{pH}$ da saliva para a neutralidade, criando um meio com menor risco para a atividade microbiana.

O queijo cuida dos dentes, determinando o fluxo salivar e crescendo o acúmulo de cálcio na placa. Isso pode ser completado com uma menor quantia de queijo $(5 \mathrm{~g})$, portanto, tendo uma recompensa mínima para o consumo de gordura. ${ }^{54}$ Os sujeitos precisam ser ensinados a comer comidas, como queijo e mastigar chicletes sem açúcar depois das refeições para inutilizar as consequências acidogênicos dos açúcares da alimentação ${ }^{55}$.

O leite de vaca tem baixo açúcar do que o leite em pó e é maior nos fatores de prevenção, cálcio e fósforo. Nenhum leite de vaca deve ser oferecido antecipadamente dos seis meses devido ao perigo de alergia e à alta carga de solutos. A partir dos seis meses, o leite de vaca pode ser acrescentado à alimentação, mas a primeira fonte de leite deve ser somente o leite materno ou a fórmula. Os dois com alto teor de ferro. Somente a partir de um ano pode ser ofertado leite de vaca integral, de dois anos, leite semidesnatado e de cinco anos, desnatado, se interessado ${ }^{50}$.

É importante evitar açúcar, café, enlatados, frituras, refrigerantes, balas, salgadinhos e guloseimas nos primeiros anos de vida. Usar sal com moderação. Cuidar da higiene no preparo e manuseio dos alimentos; e garantir armazenamento e conservação adequados.

\section{DISCUSSÃO}

A saúde bucal não deve ser vista de maneira dissociada da saúde geral. O objetivo da Odontologia não é somente preservar os dentes; ela deve ultrapassar esse limite e vislumbrar a saúde na totalidade. A cárie severa e precoce da infância representa um problema de saúde pública e exige esforço dos profissionais da saúde que atendem crianças. Tal 
doença interfere tanto na qualidade de vida da criança quanto na da família. ${ }^{56}$

$\mathrm{Na}$ infância, destacam-se como doenças bucais influenciadas pela dieta e nutrição, os defeitos na estrutura dos dentes e a cárie dentária. $\mathrm{O}$ hábito de mamar ou consumir bebidas açucaradas antes de adormecer, ou ainda durante o sono, aliado à não realização da higiene bucal adequada, é prejudicial no tocante à atividade da doença cárie. Como consequência desses hábitos de aleitamento do bebê e de uma dieta desfavorável, podem acontecer perdas dentárias precoces e alterações oclusais. A cárie dentária pode se manifestar gravemente na primeira infância e atingir graus alarmantes em determinadas situações. ${ }^{57}$

A alimentação tem um papel além da nutrição. Nos primeiros anos de vida, a variedade e a forma com que os alimentos são oferecidos influenciam a formação do gosto e a relação da criança com a alimentação. A criança que come alimentos saudáveis e adequados quando pequena tem mais chances de se tornar uma pessoa adulta consciente e autônoma para realizar boas escolhas alimentares. ${ }^{58}$

Uma alimentação adequada e saudável deve valorizar, predominantemente, alimentos in natura ou minimamente processados (como arroz, feijão, frutas, legumes e verduras, mandioca, milho, carnes e ovos). Os alimentos processados industrialmente (como enlatados, e conservas) devem ser consumidos em menor quantidade. Já os alimentos ultraprocessados (biscoitos e bolachas, sucos artificiais, refrigerantes, salgadinhos de pacote, macarrão instantâneo, guloseimas) devem ser evitados .59

Conforme o Ministério da Saúde, a introdução de alimentos complementares deve ser feita lentamente e gradual. Devem ser preparados em quantidade apropriada, fáceis de preparar a partir dos alimentos da família e com custo aceitável para a família. Para assegurar que as necessidades nutricionais da criança sejam satisfeitas os alimentos complementares devem ser introduzidos no momento certo, ser adequados, seguros do ponto de vista higiênico-sanitário e sejam adequadamente ministrados, ofertados de segundo os sinais de apetite e saciedade da criança. ${ }^{60}$

Assim, a formação de hábitos alimentares saudáveis contribui para a saúde bucal e geral e propicia uma melhor qualidade de vida para as crianças e satisfação para os pais. Tão importante quanto uma dieta saudável são os hábitos de higiene bucal. Eles são fundamentais para uma saúde bucal adequada.

Ressalta-se que a interação entre os profissionais das diversas áreas da saúde pode favorecer significativamente o desenvolvimento e estabelecimento de hábitos saudáveis e a adoção destes por parte de pais e filhos, proporcionando, assim, melhor qualidade de vida. ${ }^{61}$

\section{CONCLUSÃO}

Através da leitura e do entendimento deste trabalho, ressalta-se a importância dos profissionais da área odontológica na orientação de uma dieta saudável, com introdução de hábitos saudáveis desde os primeiros anos de vida. Além disso, instrui pais e/ou responsáveis de pacientes infantis em fase de crescimento e desenvolvimento levando conhecimento da importância de seguir as recomendações recebidas por profissionais da saúde em relação a uma alimentação saudável, a fỉm de oferecer qualidade de vida desde os primeiros anos de vida.

\section{REFERÊNCIAS}

1. Borsari, Andreia P., Cruz, Gabriela, Lolli, Juliano, Oliveira, Rosimeire R. e Santos, Silvone H. Santos. Educação nutricional para crianças de 7 a 11 anos de uma comunidade de Araraquara. UNIARA- centro universitário de Araraquara; 2005.

2. Biral, A. M. et al. Cárie dentária e práticas alimentares entre crianças de creches do município de São Paulo. Revista de Nutrição, 2013, v. 26, n. 1, p. 37-48.

3. Freire, M. cannon, G. \& sheiham, A. Análise das recomendações internacionais sobre o consumo de açúcares publicadas entre 1961 e 1991. Revista de Saúde Pública, 1994, v. 28, n. 3, p. 228-237.

4. Ramos-Gomez FJ, Weintraub JA, Gansky SA, Hoover CT, Featherstone JD. Bacterial, behavioral, and environmental factors associated with early childhood caries. J Clin Pediatr Dent. 2002, vol.26, p.165-173.

5. Joana Maranhas Fonseca da Silva. Avaliação da frequência do consumo de alimentos cariogênicos e sua relação com a cárie dentária numa amostra de crianças. Monografia (Especialização) - Curso de Ciências da Nutrição e da Alimentação, Porto: Universidade do Porto; 2006, p.52.

6. Lima Junior J.L.A. , Gonçalves L.V., Correia A.A., Alimentos x cárie: a ingestão do açúcar em excesso como fator estimulante do desenvolvimento da doença. Ciências Biológicas e da Saúde, 2.ed. Recife, 2015, v. 2, p.11-20.

7. Sheiham A., Oral health, general health and quality of life. Bull World Health Organ, 2005, v.83, n. 9, p. 644.

8. Bonecker M, Sheiham A. Promovendo saúde bucal na infância e adolescência : conhecimentos e práticas; São Paulo; Santos; 2004

9. Pine CM, Adair PM, Petersen PE, Douglass C, Burnside G, Nicoll AD, et al. Developing explanatory models of health inequalities in childhood dental caries. Community Dent Health 2004, p.86-95.

10. Freire M. Prevalência de cárie e fatores sócioeconômicos em pré-escolares: revisão de literatura. Rev Bras Odontol Saúde Coletiva. 2000, p.35-41. 
11. World Health Organization (WHO). Sugars intake for adults and children. Geneva: WHO. 2015. Disponível em:

https://www.who.int/publications/i/item/WHO-NMH-NHD-15.3

12. Sheiham A, James WP. Diet and Dental Caries: The Pivotal Role of Free Sugars Reemphasized. J Dent Res. 2015, vol.94, p.1341-7

13. Dalmolin, Viviane T. S.; Peres, Paulo E. C.; Noguera, Jorge O. C.; Açúcar e Educação Alimentar: Pode O Jovem Influenciar Essa Relação?. Monografias Ambientais, 2012, vol.10, p.2134 - 2147.

14. Vadiakas G. Case Definition, Aetiology and Risk Assessment of Early Childhood Caries (ECC): A Revisited Review. Eur Arch Paediatr Dent 2008, p.114-25.

15. Pereira DF. Fatores de risco associados à cárie dentária e ao alto nível de estreptococos mutans em crianças de 12 a 24 meses em creches do município de São Paulo - SP [doutorado]. São Paulo. Universidade de São Paulo; 2007

16. Tinanoff N, Baez RJ, Guillory CD, et al., Donly KJ, Feldens CA, McGrath C, Phantumvanit P, Pitts NB, Seow WK, Sharkov N, Songpaisan Y, Twetman S. Early childhood caries epidemiology, aetiology, risk assessment, societal burden, management, education, and policy: Global perspective. Int J Paediatr Dent. 2019, vol29, p.238-48.

17. Toledo, O,A.; Bezerra, A.C.B.; Bezerra, V.L.V.A.; et al. Cárie e Estado Nutricional- prevalência da cárie dentária relacionada com o estado nutricional em população infantil de baixa renda. RGO, 1989. v.37, n.4, p.295-8

18. Peltzer K, Mongkolchati A, Satchaiyan G, Rajchagool S, Pimpak T. Fatores sócio-comportamentais associados ao incremento de cárie: um estudo longitudinal de crianças de 24 a 36 meses na Tailândia. Int J Environ Res Saúde Pública. 2014;

19. Scalioni, Pesq Bras Odontoped Clin Integr, João Pessoa, 2012, vol.12, p.399-404.

20. Junior, JL AL. Gonçalves L V. Correia, AA. Ciências biológicas e da saúde, Recife, 2015, v. 2, p. 11-20.

21. Lanke, L.S. Influence on salivary sugar of certain properties of foodstuffs and individual oral conditions. Acta Odontol Scand, 1957, v.15, n.23.

22. Thystrup,A.; Fejerskov,O. Tratado de cariologia. Rio de Janeiro: Cultura Médica, 1988, p.388

23. Ministério da Saúde. Saúde Bucal. Brasil. Brasília: Ministério da Saúde; 2005

24. Ministério da Saúde. Saúde Bucal. Brasil. Brasília: Ministério da Saúde; 2006

25. Touger-Decker R. Nutrição para a Saúde Oral e Dental. In: Krause Alimentos. Nutrição \& Dietoterapia. $11^{\mathrm{a}}$ ed. S. Paulo: Roca; 2005. 638-645.

26. Matee, M.I.N.; Mikx, F.H.M.; Maselle, S.Y.M.; Palenstein Helderman, W.H. Mutans streptococci and lactobacilli in breast-fed children with rampant caries. Caries Res Basel, 1992.

27. Medeiros, U.V.; Souza, M.I.C.; Fonseca, C.T. Prevalência de cáries em pacientes bebês. J Bras Odontopediatr Odontol Bebê. Curitiba; 1998. v.1, n.3, p.23-34.
28. Freire MCM, Balbo PL, Amador MA, Sardinha LMV. Cad. Saúde Pública, Rio de Janeiro, 2012, vol.28, p20-29.

29. Batalha LMC. Promoção da Saúde Oral nas Crianças-da Teoria à Prática. Servir, 2001, p.159-164.

30. Mobley CC. Nutrition and dental caries. Dent Clin N Am 2003; vol.47, p.319-336.

31.Ministério da Saúde. Saúde Bucal. Brasil. Brasília: Ministério da Saúde; 2006. P. 92

32. Holt, R.D.; Moynihan, P.J. The weaning diet and dental health. Br Dent J, London, 1996. v.181, n.7, p.254-259.

33. Katz,S. A diet counseling program. J Am Dent Assoc, 1981, v.102, p.8405 .

34. Michaelsen E., Weaver L.T, Branca F, Robertson A., Feeding And Nutrition Of Infants And Young Children. Guidelines For the Who European Region With Emphasis On the Former Soviet Countries. Regional Publications, European Series, 2003, vol.87.

35. Ribeiro CC, Tabchoury CP, Del Bel Cury AA, Tenuta LM, Rosalen PL, Cury JÁ. Efeito do amido no potencial cariogênico da sacarose. 2005.

36. Lodi CS, Sassaki KT, Fraiz FC, Delbem ACB, Martinhon CCR. Evaluation of some properties of fermented milk beverages that affect the demineralization of dental enamel. Braz Oral Res, 2010, vol.24, p.95-101.

37. Velasco, L.F.L.; Rosito, D.B.; Maciel, D.L.C.; Araujo, F.B. Protocolo alimentar do bebê de zero a três anos de idade. Rev Odontopediatria 1993, v.3, n.2, p.133-139.

38. Gerstein, H. C. Cow's milk exposure and type I diabetes mellitus. a critical overview of the clinical literature. Diabetes Care, 1994, v. 17, p. 13-19.

39. Stuebe, A. M. et al. Duration of lactation and incidence of type 2 diabetes. JAMA, 2005, v. 294, p. 2601-2610.

40. Horta, B. L. et al. Evidence of the long-term effects of breastfeeding: systematic reviews and metaanalysies. Geneva. 2007

41.Biral AM, Taddei JAAC, Passoni DF, Palma D. Cárie dentária e práticas alimentares entre crianças de creches do município de São Paulo. Rev Nutr, 2013. p.37-48

42. Chaves, A. M. B.; Rosenblatt, A.; Colares, V. The importance of the weaning diet on oral health. J Bras Odontopediatr Odontol Bebê, Curitiba, 2003. v.6, n.30.

43. Ministério da Saúde. Saúde Bucal. Brasil. Brasília: Ministério da Saúde, 2002 .

44. Westover, K.M.; Diloreto, M.K.; Shearer, T.R. The relationship of breastfeeding to oral development and dental concerns. J Dent Child, Chicago,1989. v.56, n.2, p.140-143.

45. Dos Santos SP; Vieira GO; Scavuzzi AIF; Gomes Filho IS, Rev Assoc Paul Cir Dent, 2016, vol.70, p.12-18.

46. Brandão, TMG, Arciere RM, Sundefeld, MLM, Moimaz, SAS. Cárie precoce: influência de variáveis sócio-comportamentais e do locus de controle 
da saúde em um grupo de crianças de Araraquara, São Paulo, Brasil. Cad. Sáude Pública. 2006. 
47. Branco, C. A.; Valdivia, A. D. C. M.; Soares, P. B. F.; Fonseca, R. B.; Fernandes Neto, A. J.;Soares, C. J. Erosão dental: diagnóstico e opções de tratamento. Resv Odontol UNESP, 2008, v. 37, n. 3, p. 235-242.

48. Moynihan P, Petersen PE. Diet, nutrition and the prevention of dental diseases. Public Health Nutr. 2004; vol,7, p.201-26.

49. Levy SM, Warren JJ, Broffitt B, Hillis SL, Kanellis MJ. Fluoride, beverages and dental caries in the primary dentition. Caries Res. 2003; p.15765 .

50. Department of Health. Dietary reference values for food energy and nutrients in the United Kingdom. Report on health and social subjects, ed.41, London, 1991.

51. Aimutis WR. Bioactive properties of milk proteins with particular focus on aticariogenesis. J Nutr, 2004, vol.134, p.989-995.

52. Touger-Decker R, Mobley CC. Position of the American Dietetic Association: Oral health and nutrition. J Am Diet Assoc. 2003; 103(5):615-25.

53. Rugg-Gunn AJ, Roberts GJ, Wright WG. Effect of human milk on plaque $\mathrm{pH}$ in situ and enamel dissolution in vitro compared with bovine milk, lactose and sucrose. Caries Res, 1985. 19:327-34.

54. Gedalia I, Ben-Mosheh S, Biton J, Kogan D . Dental caries protection with hard cheese consumption. Am J Dent, 1994. p.331-332.

55. The Dairy Council. Diet and dental health. Topical Update. 2001.

56. Losso EM, Tavares MCR, Silva JYB, Urban CA. Severe early childhood caries: an integral approach. J Pediatr. 2009 Apr;85(4):295-300.

57. American Academy of Pediatric Dentistry. Definition oral health policies and clinical guidelines [cited 2008 Sep 26]. Available from:

URL: http://www.aapd.org/media/policies.asp.

58. Brasil. Ministério da Saúde. Guia alimentar para crianças menores de 2 anos. Brasília: Ministério da Saúde; 2002.

59. Ministério da Saúde: Guia Alimentar para População

Brasileira promovendo a alimentação saudável. Normas e manuais técnicos: Brasília, 2014.

60. Monte CMJ, Giugliani ERJ. Recomendações para alimentação complementar da criança em aleitamento materno. J Pediatr. 2004 May;80(5Supl):131-41.

61. Brasil. Ministério da Saúde. Boletim ENPACS - Estratégia Nacional Para Alimentação Complementar Saudável. Brasília, Distrito Federal. 2011. 